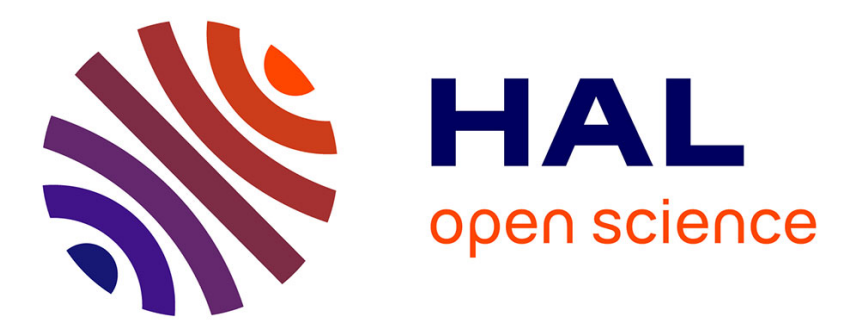

\title{
Assessment of the risk and biomechanical consequences of lateral epicondylalgia by estimating wrist and finger muscle capacities in tennis players.
}

Laurent Vigouroux, Benjamin Goislard de Monsabert, Chris Hayot, Philippe Androuet, Eric Berton

\section{To cite this version:}

Laurent Vigouroux, Benjamin Goislard de Monsabert, Chris Hayot, Philippe Androuet, Eric Berton. Assessment of the risk and biomechanical consequences of lateral epicondylalgia by estimating wrist and finger muscle capacities in tennis players.. Sports Biomechanics, 2016, 16 (4), pp.434 - 451. 10.1080/14763141.2016.1212916 . hal-01454070

\author{
HAL Id: hal-01454070 \\ https://hal.science/hal-01454070
}

Submitted on 15 Nov 2017

HAL is a multi-disciplinary open access archive for the deposit and dissemination of scientific research documents, whether they are published or not. The documents may come from teaching and research institutions in France or abroad, or from public or private research centers.
L'archive ouverte pluridisciplinaire HAL, est destinée au dépôt et à la diffusion de documents scientifiques de niveau recherche, publiés ou non, émanant des établissements d'enseignement et de recherche français ou étrangers, des laboratoires publics ou privés. 


\title{
Assessment of the risk and biomechanical consequences of lateral epicondylalgia by estimating wrist and finger muscle capacities in tennis players
}

\author{
Laurent Vigouroux, Benjamin Goislard de Monsabert, Chris Hayot, Philippe \\ Androuet \& Éric Berton
}

To cite this article: Laurent Vigouroux, Benjamin Goislard de Monsabert, Chris Hayot, Philippe Androuet \& Éric Berton (2016): Assessment of the risk and biomechanical consequences of lateral epicondylalgia by estimating wrist and finger muscle capacities in tennis players, Sports Biomechanics, DOI: 10.1080/14763141.2016.1212916

To link to this article: http://dx.doi.org/10.1080/14763141.2016.1212916

Published online: 05 Sep 2016.

Submit your article to this journal ¿

Q View related articles $\sqsubset$

View Crossmark data $₫$ 


\title{
Assessment of the risk and biomechanical consequences of lateral epicondylalgia by estimating wrist and finger muscle capacities in tennis players
}

\author{
Laurent Vigouroux ${ }^{a}$, Benjamin Goislard de Monsabert ${ }^{\mathrm{a}, \mathrm{b}}$, Chris Hayot ${ }^{\mathrm{a}}$, \\ Philippe Androuet ${ }^{c}$ and Éric Berton ${ }^{a}$
}

anstitute of Movement Sciences, National Centre for Scientific Research, Aix-Marseille University, Marseille, France; 'bepartment of Bioengineering, Imperial College London, London, UK; 'Department of Movement Sciences, Oxylane Research, Villeneuve d'Ascq, France

\begin{abstract}
Previous studies suggested that a pronounced weakness of the extensor muscles relative to the flexor muscles could increase the risk of occurrence of lateral epicondylalgia. This study investigates this hypothesis by estimating the ratio of extensor to flexor muscle capacities among healthy non-players $(n=10)$, healthy tennis players $(n=20)$, symptomatic players $(n=6)$, and players who have recovered from lateral epicondylalgia $(n=6)$. Maximum net joint moments in flexion or extension were measured during seven tasks involving the voluntary contraction of wrist and fingers. Using these data, the muscle capacities of the main muscle groups of the hand (wrist flexors, wrist extensors, finger flexors, finger extensors, and intrinsic muscles) were estimated using a musculoskeletal model. These capacities were then used to compute the extensor/flexor capacity ratios about the wrist and the finger joints. Compared to healthy nonplayers, healthy players presented higher extensor muscle capacities and greater capacity ratios showing that playing tennis generates specific adaptations of muscle capacities. Interestingly, symptomatic players, similar to those of non-players, showed more imbalanced ratios than healthy players. These results confirm that the ratio of extensor/flexor muscle capacities seems to be associated with lateral epicondylalgia and can be further used to understand its incidence and consequences.
\end{abstract}

\section{ARTICLE HISTORY}

Received 1 November 2015

Accepted 4 July 2016

\section{KEYWORDS}

Hand; net joint moments; musculoskeletal modelling; muscle capacity; elbow tendinosis

\section{Introduction}

Lateral epicondylalgia, also called 'tennis elbow', is one of the most common and painful musculoskeletal disorders of the upper limb (Coombes, Bisset, \& Vicenzino, 2012; Morris, Jobe, Perry, Pink, \& Healy, 1989). This pathology affects the tendons of the extensor carpi radialis brevis (ECRB) and longus (ECRL) as well as, in some cases, the extensor digitorum communis (EDC) (Fairbank \& Corlett, 2002). Epidemiological studies reported that 40-50\% of tennis players suffer from lateral epicondylalgia during their career (Carroll, 2006; Morris 
et al., 1989). Additionally, lateral epicondylalgia has also been associated with other activities such as building work and keyboard data entry (Haahr \& Andersen, 2003). This pathology was defined as an angiofibroblastic degeneration in response to partial lesions of the common tendon of wrist extensors (Kraushaar \& Nirschl, 1999) which are created by repeated microtraumas (Nirschl, 1973; Nirschl, 1992). In the most extreme cases, complete rupture of the tendon may occur and surgical intervention is required (Baker, Murphy, Gottlob, \& Curd, 2000).

Lateral epicondylalgia is a complex pathology which results from the combination of multiple risk factors (Gruchow \& Pelletier, 1979; Nirschl, 1973). In the context of tennis playing, the vibrational wave propagation following ball impact has been proposed as a primary risk factor (Chard \& Lachmann, 1987; Hatze, 1976; Hennig, Rosenbaum, \& Milani, 1992). However, since the pathology has also been associated with activities which do not involve any vibration phenomenon (Nirschl, 1973), this factor should rather be considered as secondary. Nevertheless, the shock wave propagation factor has been clearly associated with modifications of forearm muscle activities (Wei, Chiang, Shiang, \& Chang, 2006) and might therefore participate in the pathology development. Backhand strokes have also been assumed to be a primary factor in the pathology, mainly because they induce an eccentric stretching of wrist extensors (De Smedt, De Jong, Van Leemput, Lieven, \& Van Glabbeek, 2007; Knudson \& Blackwell, 1997; Knudson, 2004). However, as with vibration phenomenon, this factor can be considered as secondary only since lateral epicondylalgia is caused by other activities which do not involve any eccentric actions of extensor muscles, e.g. farmers and office workers (Haahr \& Andersen 2003). Moreover, even if some studies suggest that the manner in which backhand strokes are performed, e.g. using both hands or only one, could increase the risk of lateral epicondylalgia (Renstrom, 1995; Roetert, Brody, Dillman, Groppel, \& Schultheis, 1995), no epidemiological evidence has yet demonstrated the benefit or the risk of preferring one technique over the other.

Alternatively, there is a more generic explanation for lateral epicondylalgia following the overuse of wrist extensor muscles related to repetitive and intensive grip force exertions during racket or other object manipulation (Snijders, Volkers, Mechelse, \& Vleeming, 1987; Rossi, Vigouroux, Barla, \& Berton, 2014). The assumption of this explanation is initially supported by the significant electromyographic (EMG) activity measured for wrist extensor muscles (30 to $80 \%$ of the maximum EMG values) during both backhand and forehand strokes (Giangarra, Conroy, Jobe, Pink, \& Perry, 1993; Morris et al., 1989). While the activation of extensors during backhand strokes is expected due to their agonistic role in this motion, their involvement during forehand strokes, which is mostly a flexion movement, is more surprising. This phenomenon is due to the complexity of the hand musculoskeletal system. Because the tendons of the finger flexor muscles cross the wrist joint, the contractions of those muscles necessary for exerting grip forces concurrently generate a flexion moment at the wrist (Snijders et al., 1987). As the wrist balance is key in stabilising the hand and ensuring the success of the grip task, intensive actions of extensor muscles are necessary to counterbalance the undesirable wrist flexion moment created by finger flexors (Hoozemans \& Van Dieën, 2005; Mogk \& Keir, 2003). Musculoskeletal modelling of the hand showed that this phenomenon requires that wrist extensor muscles (EDC, ECRB, ECRL, and the extensor carpi ulnaris; ECU) produce forces close to their maximum force capacity during tennis forehand strokes (Rossi et al., 2014) and, more generally, during 
prehension tasks (Goislard de Monsabert, Rossi, Berton, \& Vigouroux, 2012; Goislard de Monsabert, Vigouroux, Bendahan, \& Berton, 2014).

From these previous findings, it can be hypothesised that part of the risk of lateral epicondylalgia might be related to an inability for the extensors to generate the appropriate muscle force intensities to counteract the flexor muscle actions naturally induced while gripping and manipulating a tennis racket (Kaplan, 1965; Rossi et al., 2014; Strizak, Gleim, Sapega, $\&$ Nicholas, 1983). Assessing the relative force-generating capacity between extensor and flexor muscles, referred to as 'muscle capacity ratio' in this article, therefore appears pertinent in investigating lateral epicondylalgia risks and muscular adaptations resulting from playing tennis. Previous assessments of upper limb muscle capacity ratio were based only on maximum isometric net joint moments (Alizadehkhaiyat, Fisher, Kemp, Vishwanathan, \& Frostick, 2007, 2009; Coombes et al., 2012) or EMG activity (Bazzucchi, Riccio, \& Felici, 2008). However, these previous studies suffered from several limitations in their assessment of muscle capacity. The EMG approach is questionable because the relationship between EMG and muscle force remains limited, mainly because of the uncertain nature of the signal as well as the issues related to its normalisation (Rao, Amarantini, \& Berton, 2009) and distortion (De Luca \& Merletti, 1988). Similarly, approaches using only net joint moment to assess muscle capacities can result in significant inaccuracies. Because co-contraction is inevitable, maximum isometric net joint moments always include the conjoint actions of both agonist and antagonist muscle groups, and might therefore inadequately represent agonist muscle capacity (Amarantini \& Martin, 2004). In order to improve the assessment of muscle capacity, methods have been developed to estimate the individual contributions of agonist and antagonist muscle groups using a combination of net joint moments and EMG signals as inputs for musculoskeletal models (Amarantini \& Martin, 2004; Olney \& Winter, 1985; Rao et al., 2009; Vigouroux, Goislard de Monsabert, \& Berton, 2015). The use of such methods might therefore be more appropriate for investigating muscle capacity ratio with regard to the occurrence of lateral epicondylalgia.

This current study investigated the muscle capacities and the extensor/flexor muscle capacity ratios about the wrist and finger joints in one group of healthy non-players and three groups of tennis players comprising healthy players, players currently injured by lateral epicondylalgia and players who had recovered from lateral epicondylalgia. The objective of this study was to determine the adaptations of hand muscle capacities that could result from several years of playing tennis and to determine in what proportion the muscle capacity ratio could be associated with the occurrence of lateral epicondylalgia. A musculoskeletal model of the hand was used conjointly with a set of measurements of maximum net joint moments to estimate the muscle force capacities and the muscle capacity ratios at the wrist and metacarpophalangeal (MCP) joints. Given the predominant action of extensors when manipulating a racket, we hypothesised that the muscle capacity ratios are significantly modified by tennis experience and modified according to the pathology history of the players.

\section{Methods}

\section{Participants}

Forty-two males, including 32 tennis players and 10 non-players, volunteered to participate in this study. The 'Healthy non-players' group comprised ten male participants (age: 
$26.8 \pm 3.6$ years; height: $178.0 \pm 5.8 \mathrm{~cm}$; body mass: $69.2 \pm 6.0 \mathrm{~kg}$; hand length: $18.8 \pm 1.0 \mathrm{~cm}$ ) not involved in any activity requiring intensive use of the finger and wrist muscles. Tennis players were divided into three groups: 20 healthy tennis players with no history of lateral epicondylalgia ('Healthy tennis players', age: $22.3 \pm 9.5$ years; height: $177.5 \pm 6.7 \mathrm{~cm}$; body mass: $67.5 \pm 9.0 \mathrm{~kg}$; hand length: $19.4 \pm 1.1 \mathrm{~cm}$ ), six tennis players currently suffering from chronic lateral epicondylalgia ('Symptomatic players', age: $27.5 \pm 8.4$ years; height: $180.7 \pm 7.6 \mathrm{~cm}$; body mass: $72.5 \pm 8.5 \mathrm{~kg}$; hand length: $19.2 \pm 0.7 \mathrm{~cm}$ ), and six tennis players who had recovered from lateral epicondylalgia ('Recovered players', age: $21.2 \pm 4.2$ years; height: $186.2 \pm 11.5 \mathrm{~cm}$; body mass: $79.0 \pm 11.9 \mathrm{~kg}$; hand length: $20.0 \pm 1.6 \mathrm{~cm}$ ). All tennis players trained at least four hours a week for three years, and were classified as intermediate or advanced players according to the International Tennis Number (ITN between 7 and 3). The player skill-levels were similar in the three groups. The criterion for inclusion in the Symptomatic group was that the participant was currently experiencing at least one of the following symptoms: laterally localised pain at the elbow, tenderness at the lateral epicondyle and/or pain with extension of the wrist or the fingers. The inclusion criterion in the Recovered group was that the lateral epicondylalgia should have been diagnosed and clinically treated during the last 3 years before the experiment. The ethics committee of Aix-Marseille University approved the testing protocol and a written informed consent was obtained from each participant before testing.

\section{Measurement of maximum net joint moments}

A method previously used to investigate muscle capacities in rock-climbers (Vigouroux et al., 2015) has been adapted for this study. A hand-wrist ergometer (Bio2 M, Compiegne, France) measured the net isometric flexion and extension moments about the wrist and the MCP joints at $2000 \mathrm{~Hz}$ (Figure 1A). During all trials, the participant's position was such that the wrist was at $0^{\circ}$ of both flexion and abduction with the forearm in neutral pronation; the elbow was at $90^{\circ}$ of flexion and the shoulder was at $0^{\circ}-15^{\circ}$ of abduction and neutral flexion and rotation. The ergometer was fixed onto a wall and positioned according to the participant's height to ensure a horizontal position of the right forearm while conforming to the posture described above. Participants were asked to exert a maximum isometric joint moment about the MCP joints or about the wrist for six seconds. A resting period of one minute separated consecutive trials to limit the effects of fatigue.

The ergometer was used with four different modules which tested specific hand and finger muscle groups during maximum flexion or extension isometric moment exertion. Participants exerted isometric actions on the modules using either the palmar side of the hand/fingers for flexion moments or the dorsal side for extension moments. Participants were instructed to involve only their hand and fingers and to avoid any participation of the elbow, shoulder, trunk or legs. Although actions of synergist and antagonist muscles could not be excluded, the four modules were designed to provide maximum involvement of the targeted muscle group(s). The testing of multiple joints and tasks results in a strength profile that was further used by the model to assess the individual capacity of each muscle group. The modules were used as follows:

(i) The first module completely encased the hand palm between the MCP joint of the thumb and those of the four long fingers (Figure 1B). This module was used during 

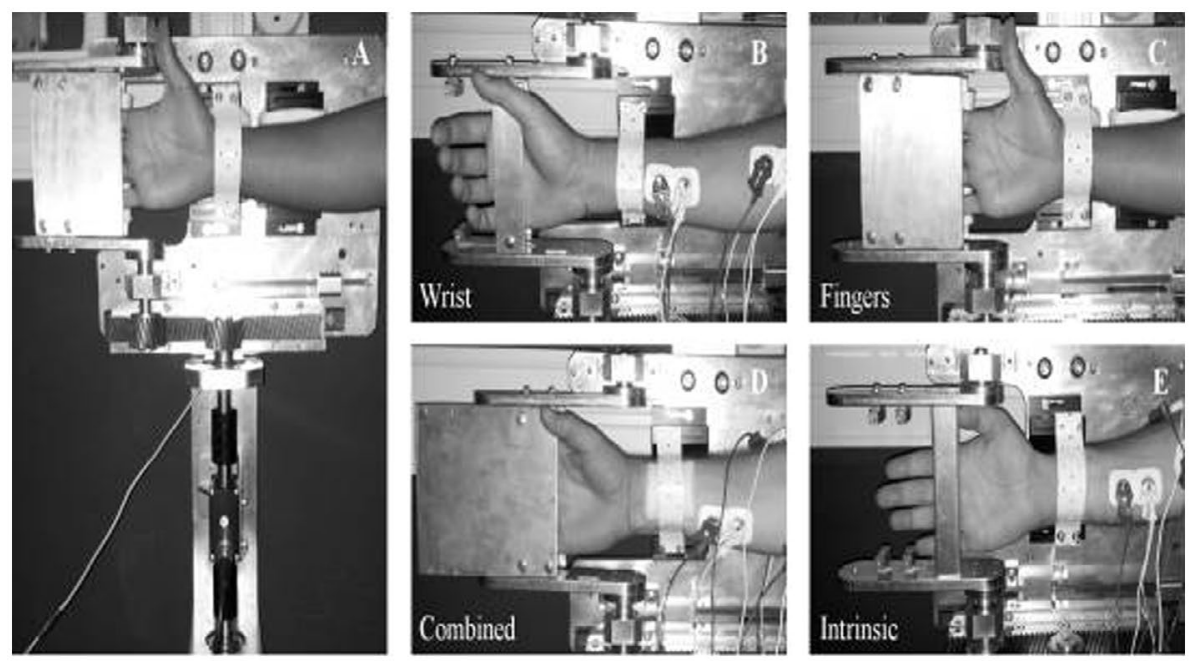

Figure 1. Experimental set-up. These pictures show the specially-designed ergometer $(A)$ as well as the modules and associated postures $(B, C, D$, and $E$ ) used to realise the isometric maximal voluntary contractions.

the 'Wrist' tasks which consisted in exerting either flexion $\left(W_{\text {flex }}\right)$ or extension $\left(W_{\text {ext }}\right)$ moments about the wrist and aimed to involve only those muscles acting about the wrist. The module was designed such that the fingers were not in contact with the module, thereby minimising the actions of extrinsic finger muscles.

(ii) The second module encased the hand and fingers from the palm of the hand to the tips of the fingers (Figure 1D). It was used to measure the combined actions of extrinsic finger muscles and wrist-specific muscles. The 'Combined' tasks corresponded to the exertion of flexion $\left(C_{\text {flex }}\right)$ and extension $\left(C_{\text {ext }}\right)$ moments about the wrist.

(iii) The third module encased the four long fingers from the MCP joint line to the fingertips (Figure 1C). It was used during the 'Finger' tasks which consisted in exerting either flexion $\left(F_{\text {flex }}\right)$ or extension $\left(F_{\text {ext }}\right)$ moments about the MCP joints and aimed at maximally targeting the finger extrinsic muscles as well as the intrinsic muscles.

(iv) The last module was placed under the proximal phalanx palmar side of the long fingers, distally to the MCP joints, such that DIP and PIP joints were free. It was used during the 'Intrinsic' task $\left(F_{\text {int }}\right)$ which consisted in exerting a flexion moment about the MCP joints. The aim of this module was to involve the intrinsic muscles (Figure 1E).

\section{EMG recordings}

The levels of EMG activity of the ECRL, EDC, flexor carpi radialis (FCR), and flexor digitorum superficialis (FDS) muscles were recorded using a Biopac MP150 system (Biopac Systems, Inc. Santa Barbara, CA, USA) sampling at $2000 \mathrm{~Hz}$. Surface electrodes (9-mm diameter) were positioned over the muscle bellies after skin abrasion and cleaning with 


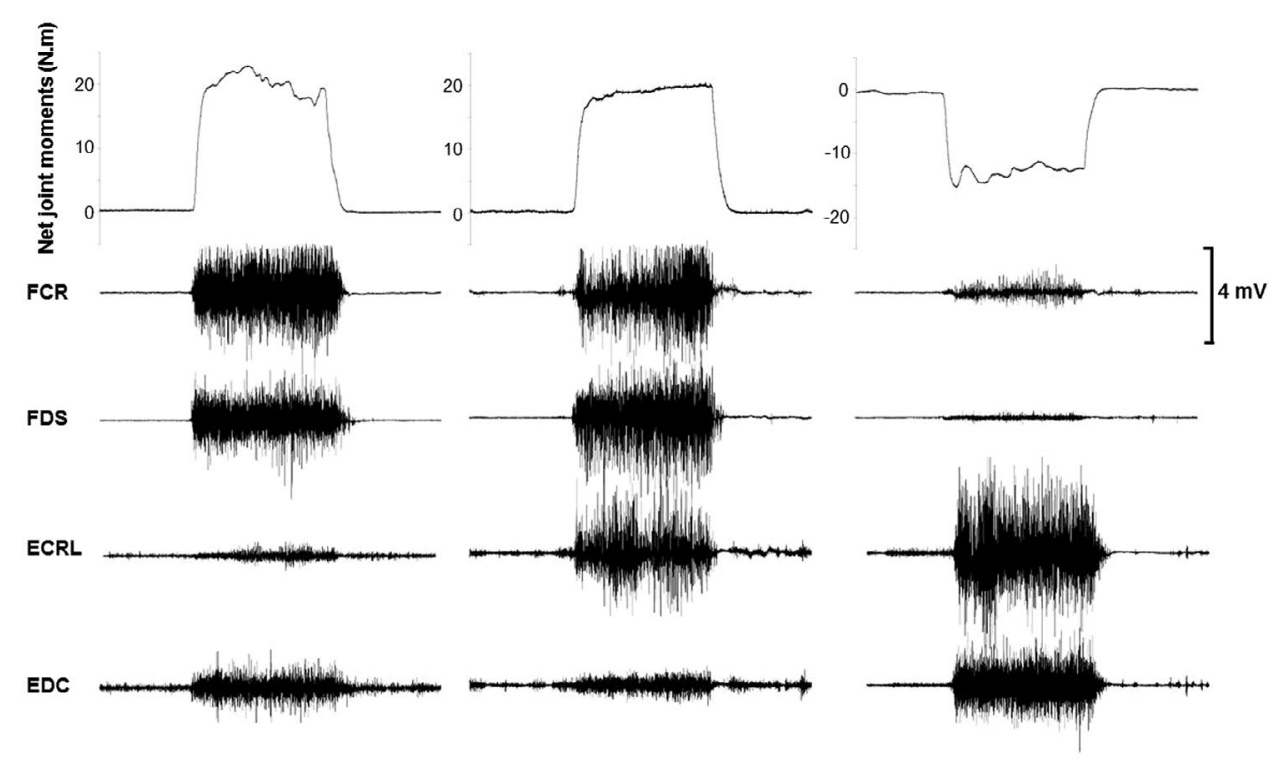

Figure 2. Representative net joint moment data recorded by the ergometer (top panels) and associated EMG recordings of the four representative muscles (FCR, FDS, ECRL, EDC) during the wrist flexion task (left panels), finger flexion task (middle panels), and wrist extension task (right panels). The EMG recordings clearly indicate that the activation levels of synergist and antagonist muscles are non-negligible and therefore justify the need for a musculoskeletal model to estimate the capacities of specific muscle groups instead of only using the resultant net joint moments.

alcohol. Electrodes were placed as in Vigouroux et al., (2015) and their placement was checked by asking participants to execute a series of contractions targeting specific flexor or extensor muscle groups about either the wrist or the MCP joints. EMG signals were filtered using a Butterworth filter (bandpass, 4th order, zero phase lag, bandwidth 20-400 Hz). Figure 2 shows an example of typical recordings for one participant during the wrist flexion task (left panels), the finger flexion task (middle panels), and the wrist extension task (right panels). In addition to the ergometer tasks, two trials were performed with zero net joint moments to measure the ratio of coactivation between forearm extensor and flexor muscles (Falconer \& Winter, 1985). During this 'Co-contraction' task (Co), the participants were asked to maximally and statically co-contract all hand and forearm muscles with a similar arm, forearm and hand posture to the one used during ergometer tasks.

\section{Data analysis and estimation of muscle capacities}

For each condition, only the trial presenting the highest measured joint moment was considered for the analysis. The maximum isometric joint moments were evaluated using a $750 \mathrm{~ms}$ window centred on the peak moment for each task (Valero-Cuevas, Zajac, \& Burgar, 1998). The samples over this time interval were used to compute the mean joint moment as well as the EMG root mean square (RMS) value. For each muscle, the muscle activation was assessed by normalising the RMS value during each task by the highest RMS value recorded among all trials and all time samples. The initial maximum capacities $\left(M_{\max \mid g}^{\text {init }}\right)$ of the five $g$ muscle groups (Wrist Flexors, WF; Wrist Extensors, WE; Finger Flexors, FF; 
Table 1. Muscle groups used in the optimisation process.

\begin{tabular}{|c|c|}
\hline Muscle Group & Included Muscles \\
\hline WF Wrist Flexors & flexor carpi radialis; flexor carpi ulnaris; palmaris longus \\
\hline WE Wrist Extensors & extensor carpi radialis brevis, extensor carpi radialis longus, extensor carpi ulnaris \\
\hline FF Finger Flexors & $\begin{array}{l}\text { flexor pollicis longus; flexor digitorum profundus of Index, Middle, Ring, and Little fingers; flexor } \\
\text { digitorum superficialis of Index, Middle, Ring, and Little fingers }\end{array}$ \\
\hline FE Finger Extensors & $\begin{array}{l}\text { extensor pollicis longus and brevis; adductor pollicis longus; extensor digitorum communis of Index, } \\
\text { Middle, Ring, and Little fingers, extensor indicis proprius, extensor digiti quinti }\end{array}$ \\
\hline FI Intrinsic & $\begin{array}{l}\text { 1st, } 2 \text { nd, 3rd, 4th dorsal interossei; 1st, 2nd, 3rd palmar interossei; 1st, 2nd, 3rd, 4th lumbrical, flexor } \\
\text { digiti quinti, abductor digiti quinti }\end{array}$ \\
\hline
\end{tabular}

Finger Extensors, FE; Intrinsic, FI) were evaluated using a musculoskeletal model of the hand including $42 \mathrm{~m}$ muscles (Table 1 and Equation (1)). To this end, the muscle-moment generating capacities of each muscle $\left(M_{\max \mid g}^{\text {init }}\right)$ were initially evaluated according to Equation (2) as was classically done for a generic musculoskeletal model of the hand (Sancho-Bru, Perez-Gonzalez, Vergara, \& Giurintano, 2003; Valero-Cuevas et al., 1998):

$$
\begin{gathered}
M_{\max \mid g}^{\text {init }}=\sum_{m} M_{\max \mid m}^{\text {init }} \text { with } g=\{\mathrm{WF} ; \mathrm{WE} ; \mathrm{FF} ; \mathrm{FE} ; \mathrm{FI}\} \\
M_{\max \mid m}^{\mathrm{init}}=r_{m} \cdot \mathrm{PCSA}_{m} \cdot \sigma_{\max }
\end{gathered}
$$

where the maximum muscle stress value $\left(\sigma_{\max }\right)$ is a constant, usually set at $35.4 \mathrm{~N} / \mathrm{cm}^{2}$ for hand muscles (Valero-Cuevas et al., 1998). $r_{m}$ and PCSA ${ }_{m}$ are the flexion/extension moment arm about either the wrist or MCP joint and the physiological cross-sectional area of the $m$ muscle. PCSA data was taken from Chao, An, Cooney, and Linscheid (1989) for the fingers, and from Ramsay, Hunter, and Gonzalez (2009) for the wrist. Depending on the posture adopted during this experiment, muscle moment arms were computed assuming a neutral position ( $0^{\circ}$ in flexion-extension, abduction-adduction, and pronation-supination) for all joints using the data from Chao et al. (1989) for the fingers, and from Lemay and Crago (1996) for the wrist. Moment arms about the finger joints were scaled for each participant using their hand length (Chao et al., 1989).

To assess personalised muscle capacities for each of the tested participants, the PCSA data and the $\sigma_{\max }$ value of Equation (2) were adjusted using an optimisation procedure. The procedure consisted in determining for each participant a new $\sigma_{\max }$ value and five PCSA coefficients $\left(c_{g}\right)$. Each PCSA coefficient was used to multiply the PCSA of the muscles from one of the five muscle groups used in the procedure (WF, WE, FF, FE, and FI) such that:

$$
M_{\max \mid g}^{\mathrm{adj}}=\sum_{m} r_{m} \cdot c_{g} \cdot \mathrm{PCSA}_{m} \cdot \sigma_{\max }^{\mathrm{adj}}
$$

The $\sigma_{\max }^{\mathrm{adj}}$ and $c_{g}$ values were adjusted for each participant such that the model was able to reproduce the net moments effectively measured with the ergometer. The net moment measured during one of the eight tasks is denoted $M_{\text {ergo }}$ (task) with task $=\left\{W_{\text {flex }} ; W_{\text {ext }} C_{\text {flex }} ; C_{\text {ext }} ; F_{\text {flex }} ; F_{\text {ext }} ; F_{\text {int }} ; C o\right\}$ while its estimate using the musculoskeletal model is denoted $\overline{M_{\text {ergo }}}($ task) and calculated using the equation

$$
\overline{M_{\text {ergo }}}\left[\sigma_{\max }^{\text {adj }}, c_{g}, a_{\text {mech }}(\text { task })\right]=\sum_{g} a_{\text {mech } \mid g}(\text { task }) \cdot M_{\max \mid g}^{\text {adj }}
$$


where $a_{\text {mech } \mid g}$ (task) is the mechanical activation of the $g$ muscle group with $g=\{\mathrm{WF} ; \mathrm{WE} ; \mathrm{FF} ; \mathrm{FE} ; \mathrm{FI}\}$. The mechanical activation $a_{\text {mech } \mid g}($ task $)$ is a value between 0 and 1 which indicates at what percentage of its maximum capacity $\left(M_{\max \mid g}^{\text {adj }}\right)$ a muscle group is producing a moment during a task. The $c_{g}$ coefficients, the $\sigma_{\max }^{\text {adj }}$ value, and $a_{\text {mech } \mid g}($ task) were determined using a non-linear least-squares constrained optimisation technique (Fmincon, optimisation toolbox, Matlab, Natick, Massachusetts USA) with upper and lower bounds formulated as follows:

find

$$
\begin{gathered}
\sigma_{\mathrm{max}}^{\mathrm{adj}} \\
c_{g}=\left\{c_{\mathrm{WF}} ; c_{\mathrm{WE}} ; c_{\mathrm{FF}} ; c_{\mathrm{FE}} ; c_{\mathrm{FI}}\right\} \\
a_{\text {mech }}=\left\{a_{\text {mech } \mid \mathrm{WF}}(\text { task }) ; a_{\text {mech } \mid \mathrm{WE}}(\text { task }) ; a_{\mathrm{mech} \mid \mathrm{FF}}(\text { task }) ; a_{\text {mech } \mid \mathrm{FE}}(\text { task }) ; a_{\text {mech } \mid \mathrm{FI}}(\text { task })\right\}
\end{gathered}
$$

that minimise

$$
f\left(\sigma_{\text {max }}^{\text {adj }}, c_{g}, a_{\text {mech }}\right)=\sum_{\text {task }}\left[M_{\text {ergo }}(\text { task })-\overline{M_{\text {ergo }}}\left[\sigma_{\text {max }}^{\text {adj }}, c_{g}, a_{\text {mech }}(\text { task })\right]\right]^{2}
$$

subject to

$$
\left\{\begin{array}{c}
15<\sigma_{\max }^{\mathrm{adj}}<60 \\
0.5<c_{g}<8 \\
0<a_{\text {mech }}<1
\end{array}\right.
$$

and subject to

$$
\begin{aligned}
& 0.7 \frac{M_{\text {ergo }}\left(\mathrm{C}_{\text {ext }}\right)}{M_{\text {ergo }}\left(\mathrm{C}_{\text {flex }}\right)} \leq \frac{M_{\max \mid W E}+M_{\max \mid F E}}{M_{\max \mid W F}+M_{\max \mid F F}} \leq 1.3 \frac{M_{\text {ergo }}\left(\mathrm{C}_{\text {ext }}\right)}{M_{\text {ergo }}\left(\mathrm{C}_{\text {flex }}\right)} \\
& 0.7 \frac{M_{\text {ergo }}\left(F_{\text {ext }}\right)}{M_{\text {ergo }}\left(F_{f l e x}\right)} \leq \frac{M_{\text {max } \mid \mathrm{FE}}}{M_{\text {max } \mid \mathrm{FF}}+M_{\max \mid \mathrm{FI}}} \leq 1.3 \frac{M_{\text {ergo }}\left(F_{\text {ext }}\right)}{M_{\text {ergo }}\left(F_{f l e x}\right)} \\
& 0.7 \frac{M_{\text {ergo }}\left(W_{\text {flex }}\right)}{M_{\text {ergo }}\left(C_{f l e x}\right)} \leq \frac{M_{\text {max } \mid \mathrm{WF}}}{M_{\text {max } \mid \mathrm{WF}}+M_{\text {max } \mid \mathrm{FF}}} \leq 1.3 \frac{M_{\text {ergo }}\left(W_{\text {flex }}\right)}{M_{\text {ergo }}\left(C_{f l e x}\right)} \\
& 0.7 \frac{M_{\text {ergo }}\left(W_{\text {ext }}\right)}{M_{\text {ergo }}\left(C_{\text {ext }}\right)} \leq \frac{M_{\text {max } \mid \mathrm{WE}}}{M_{\text {max } \mid \mathrm{WE}}+M_{\text {max } \mid \mathrm{FE}}} \leq 1.3 \frac{M_{\text {ergo }}\left(W_{\text {ext }}\right)}{M_{\text {ergo }}\left(C_{\text {ext }}\right)}
\end{aligned}
$$


The initial values used in the optimisation for $\sigma_{\max }^{\text {adj }}$ and $c_{g}$ were $35.4 \mathrm{~N} / \mathrm{cm}^{2}$ and 1 , respectively. Each $a_{\text {mech } \mid g}($ task) initial value was equal to the EMG activity of the associated muscle during the task. All the initial values were carefully chosen to obtain the most physiologically realistic results. The constraints of Equation (7) were added to avoid unrealistic distribution of muscle capacities. They consisted in constraining ratios of estimated muscle capacities, e.g. flexor/extensor or flexor/flexor, with ratios of measured net moment values. These equations prevented large inconsistencies between the distribution of estimated muscle capacities and the profile of measured net moments. To assess the validity of the obtained results, the absolute differences between the estimated mechanical activations $\left(a_{\text {mech } \mid g}(\operatorname{task})\right)$ and the

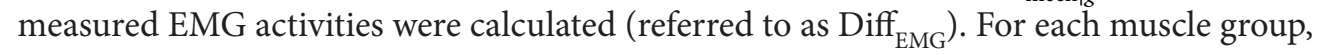
this value was averaged among all tasks and all participants. No Diff ${ }_{\mathrm{EMG}}$ was computed for the Intrinsic muscle group because no EMG was collected for these muscles.

Using the estimated muscle capacities, the muscle capacity ratio between extensor and flexor muscles about the wrist $\left(\right.$ Mratio $\left._{\text {wrist }}\right)$ and the MCP joints $\left(\right.$ Mratio $\left._{\text {mcp }}\right)$ was computed as follows:

$$
\begin{gathered}
M_{\text {ratio }_{\text {wrist }}}=\frac{M_{\max \mid \mathrm{WE}}+M_{\max \mid \mathrm{FE}}}{M_{\max \mid \mathrm{WF}}+M_{\max \mid \mathrm{FF}}} \\
\text { Mratio }_{\mathrm{mcp}}=\frac{M_{\max \mid \mathrm{FE}}}{M_{\max \mid \mathrm{FF}}+M_{\max \mid \mathrm{FI}}}
\end{gathered}
$$

\section{Statistical analysis}

Mean and standard deviation $( \pm)$ were computed for each group of participants. The results were checked for normality and homogeneity of variance. ANOVA (Statistica, Statsoft, Tulsa, USA) were used to identify significant differences among participant groups (Healthy non-tennis players, Healthy tennis players, Symptomatic players, Recovered players) for the maximum joint moment of the seven tasks $\left(W_{\text {flex }}, W_{\text {ext, }} C_{\text {flex }}, C_{\text {ext, }}, F_{\text {flex }}, F_{\text {ext, }} F_{\text {int }}\right)$, the estimated moment-generating capacities of the muscle groups at the wrist (WF, WE; FF, $\mathrm{FE}$ ) and the MCP joints (FF, FE, FI) and the muscle capacity ratios at the wrist and MCP joints. The significance level was set at $p<0.05$ and a Holm-Bonferroni's adjustment was made. Newman-Keuls was used post hoc to identify the differences between the samples when ANOVA showed significant effects.

\section{Results}

\section{Measured net joint moments}

Measured net joint moments are shown in Figure 3. A significant effect of participant groups was found on isometric flexion strength during the Wrist and the Combined tasks $(F(3$, $38)=6.63 ; p=1.0 \times 10^{-3}$ and $F(3,38)=3.82 ; p=1.7 \times 10^{-2}$, respectively). In both these tasks, Symptomatic players exerted higher net joint moments compared with the other participant groups. During the Wrist flexion task, Symptomatic players exerted net joint moment amounting to $17.9 \pm 3.9 \mathrm{Nm}$ while Healthy non-tennis players, Healthy tennis players, 


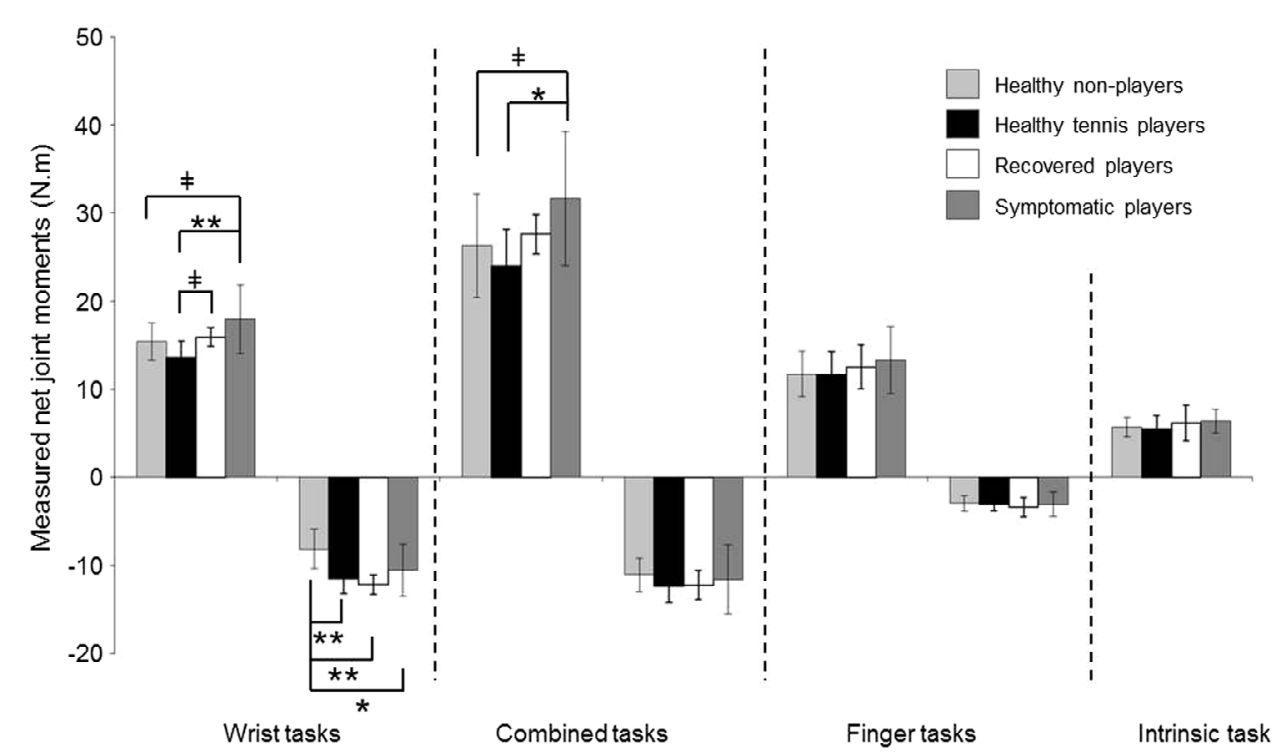

Figure 3. Results of measured net joint moments. The clear grey blocks represent the Healthy non-players, the black blocks represent the Healthy tennis players, the white blocks represent the Recovered players, and the dark grey blocks represent the Symptomatic players. Positive values represent flexion moments, negative values represent extension moments. Significant differences between the indicated participant groups were noted $(* *: p<0.01 ; *: p<0.05 ; \neq: p<0.1)$.

and Recovered players exerted $15.4 \pm 2.1 \mathrm{Nm}, 13.6 \pm 1.9 \mathrm{Nm}, 15.9 \pm 1.1 \mathrm{Nm}$, respectively. During the Combined flexion task, Symptomatic players exerted on average $31.6 \pm 7.6 \mathrm{Nm}$ while other participants exerted $26.3 \pm 5.9 \mathrm{Nm}, 24.0 \pm 4.1 \mathrm{Nm}, 27.6 \pm 2.2 \mathrm{Nm}$ for Healthy non-players, Healthy tennis players, and Recovered players, respectively. Concerning extension net moments, a significant effect of participant groups was only found for the Wrist task $\left(F(3,38)=8.03 ; p=2.9 \times 10^{-4}\right)$. Healthy non-players exerted $-8.1 \pm 2.2 \mathrm{Nm}$ while Healthy players, Recovered players, and Symptomatic players exerted $-11.5 \pm 1.7 \mathrm{Nm}$, $-12.2 \pm 1.1 \mathrm{Nm},-10.6 \pm 2.9 \mathrm{Nm}$, respectively. No significant effect was found for the Combined extension task, for both Finger tasks as well as for the Intrinsic task $(p>0.05)$.

\section{Estimated muscle moment-generating capacities}

The estimated moment-generating capacities of muscle groups about the wrist and MCP joints are presented in Figure 4. For wrist muscles, a significant effect of participant groups was found in the capacities of both flexor $\left(F(3,38)=5.12 ; p=4.5 \times 10^{-3}\right)$ and extensor muscle groups $\left(F(3,38)=12.29 ; p=9.0 \times 10^{-6}\right)$. High wrist flexor capacities were observed in both Symptomatic and Recovered players $(34.3 \pm 3.8 \mathrm{Nm}$ and $37.2 \pm 7.3 \mathrm{Nm}$, respectively) compared with Healthy tennis players and Healthy non-players $(29.7 \pm 4.2 \mathrm{Nm}$ and $29.7 \pm 4.2 \mathrm{Nm}$, respectively). The wrist extensor capacity was higher (in absolute value) among Recovered players $(-21.5 \pm 2.8 \mathrm{Nm})$ and Healthy tennis players $(-19.2 \pm 2.2 \mathrm{Nm})$ than for Healthy non-players $(-14.6 \pm 2.5 \mathrm{Nm})$ and Symptomatic players $(-16.7 \pm 3.1 \mathrm{Nm})$. Concerning the finger muscles, participant groups showed no significant effect on the 


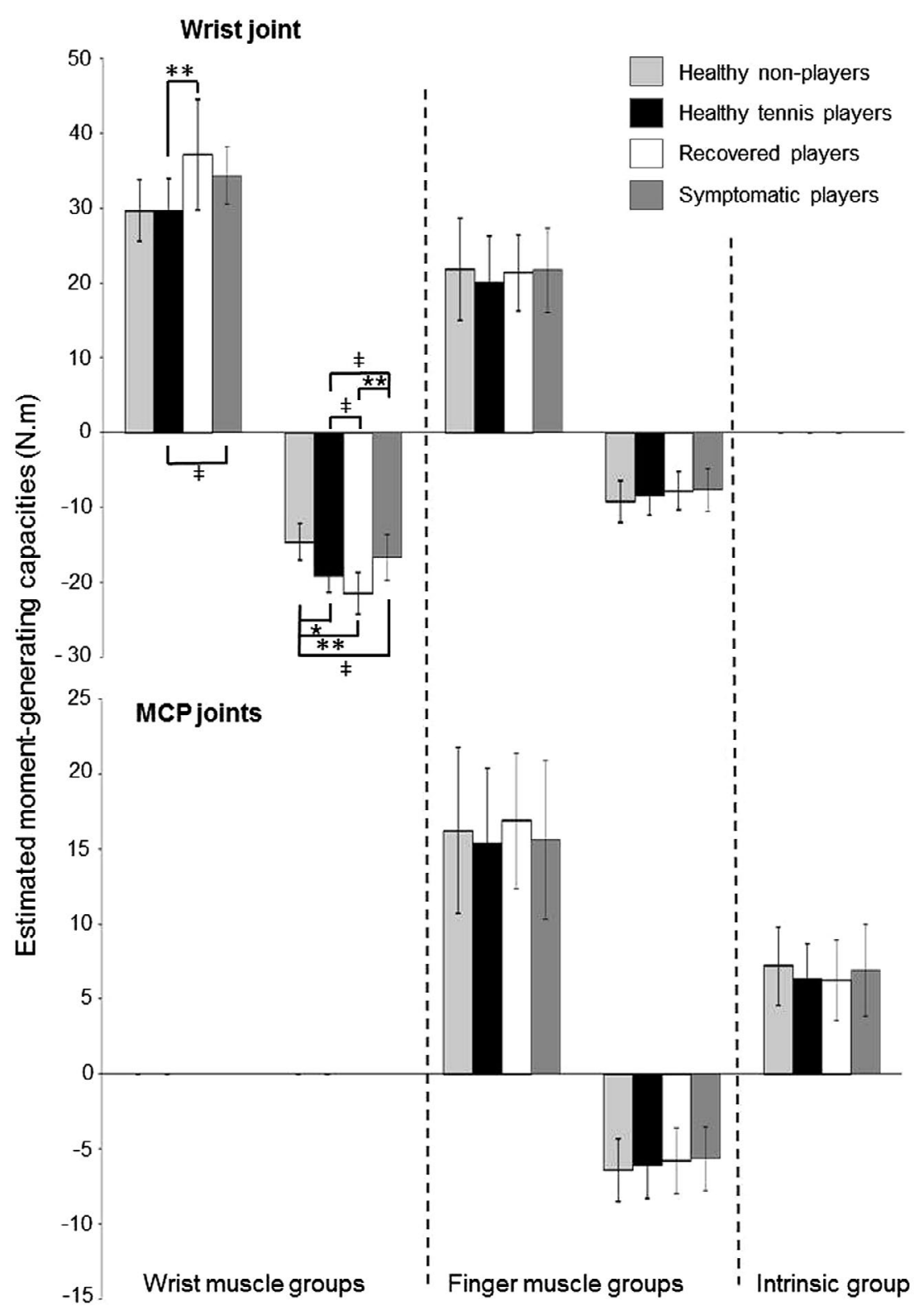

Figure 4. Estimated muscle moment-generating capacities at the wrist joint level (upper panel) and MCP joints level (lower panel). Muscles included in the different muscle groups are detailed in Table 1. The Healthy non-players are represented by the clear grey blocks, the Healthy tennis players are in black, the Recovered players are in white, and the Symptomatic players are represented by dark grey blocks. Significant differences between the indicated participant groups were noted $\left(^{* *}: p<0.01 ; *: p<0.05 ; \neq\right.$ : $p<0.1)$. Flexion and extension are positive and negative values, respectively. No muscle capacities were presented for the intrinsic muscle group at the wrist joint and for the wrist muscle groups at the MCP joints since these muscles do not cross these respective joints.

capacities of finger flexors $(19.3 \pm 6.6 \mathrm{Nm}$ at wrist joint $)$, finger extensors $(-7.8 \pm 2.8 \mathrm{Nm}$ at wrist joint), or intrinsic muscles $(6.2 \pm 2.6 \mathrm{Nm}$ at MCP joints). 
Table 2. Mean ( \pm ) estimated parameters for the musculoskeletal model. Cg represents the PCSA coefficients adapted to each participant for each muscle group. $\sigma_{\max }^{\text {adj }}$ represents the maximum muscle stress coefficient adapted for each participant and used for all muscle groups. Diff ${ }_{E M G}$ represents the mean (among all tasks and all participants of a participant group) of the differences between the estimated mechanical activation of each muscle group and the recorded EMG activity. No EMG was recorded for the intrinsic muscle group.

\begin{tabular}{|c|c|c|c|c|c|c|}
\hline & & Wrist Flexors & $\begin{array}{l}\text { Wrist Exten- } \\
\text { sors }\end{array}$ & Finger Flexors & Finger Extensors & Intrinsic \\
\hline \multirow[t]{2}{*}{ Healthy non-players } & $\begin{array}{l}\mathrm{Cg} \\
\sigma_{\max }^{\text {adj }}\end{array}$ & $5.22(0.57)$ & $4.81(0.61)$ & $\begin{array}{l}1.46(0.36) \\
30.7(3.2)\end{array}$ & $2.66(0.76)$ & $2.41(0.96)$ \\
\hline & $\operatorname{miff}_{\text {mGG }}$ & $0.15(0.04)$ & $0.14(0.05)$ & $0.14(0.04)$ & $0.27(0.04)$ & / \\
\hline Healthy tennis players & & $5.02(0.68)$ & $6.07(0.63)$ & $\begin{array}{c}1.29(0.38) \\
30.75(2.76)\end{array}$ & $2.30(0.64)$ & $1.94(0.73)$ \\
\hline Recovered players & & $\begin{array}{l}0.13(0.04) \\
6.00(1.10)\end{array}$ & $\begin{array}{l}0.16(0.06) \\
6.51(0.53)\end{array}$ & $\begin{array}{c}0.16(0.05) \\
1.33(0.31)\end{array}$ & $\begin{array}{l}0.25(0.05) \\
2.05(0.69)\end{array}$ & $\begin{array}{c}\text { I' } \\
1.77(0.74)\end{array}$ \\
\hline \multirow[t]{2}{*}{ Symptomatic players } & $\begin{array}{l}\sigma_{\max } \\
\mathrm{Diff}_{\text {EMG }} \\
\mathrm{Cg} \\
\sigma_{\max }^{\text {adj }}\end{array}$ & $\begin{array}{l}0.13(0.04) \\
5.93(0.88)\end{array}$ & $\begin{array}{l}0.16(0.05) \\
5.62(0.95)\end{array}$ & $\begin{array}{c}0.14(0.03) \\
1.54 \pm 0.29) \\
30.25(2.51)\end{array}$ & $\begin{array}{l}0.29(0.04) \\
2.22(0.68)\end{array}$ & $\begin{array}{c}\text { ' } \\
2.05(1.10)\end{array}$ \\
\hline & Diff $_{E M G}$ & $0.13(0.06)$ & $0.20(0.20)$ & $0.11(0.06)$ & $0.30(0.10)$ & I \\
\hline
\end{tabular}

Table 2 provides the mean estimated parameters $\left(c_{g}\right.$ and $\left.\sigma_{\max }^{\mathrm{adj}}\right)$ that were used to compute the muscle capacities given above. As expected, the changes in $c_{g}$ coefficients and $\sigma_{\max }$ values among the tested participant groups lead to similar conclusions as when comparing muscle capacities. These variables are indeed strongly related through Equation (5). The average differences between mechanical activations and EMG recordings during each task ranged from 0.11 to 0.30 . The highest values were observed for the finger extensor muscle group with mean values ranging from 0.25 to 0.30 . The lowest difference between mechanical activations and EMG recordings was observed for the finger and wrist flexors (values ranging from 0.11 to 0.16 ).

\section{Muscle ratios of extensor/flexor capacities}

Muscle capacity ratios at wrist and MCP joints are shown in Figure 5. A ratio less than 1 indicates that the joint presents an imbalanced capacity ratio with stronger capacities for flexor than for extensor muscles. The ANOVA showed a significant effect of participant groups on the wrist muscle capacity ratio $\left(F(3,38)=5.08 ; p=4.7 \times 10^{-3}\right)$. All wrist capacity ratios were less than 1 , meaning that wrist extensors were weaker than wrist flexors in all tested participant groups. Healthy tennis players showed the highest ratios amounting to $0.57 \pm 0.10$. Recovered players and Non-players showed intermediate ratios amounting to $0.50 \pm 0.04$ and $0.47 \pm 0.07$. Interestingly, the muscle capacity ratios of the Symptomatic players were the lowest $(0.43 \pm 0.07)$ and were on average $23.2 \%$ lower than those of Healthy tennis players. At MCP joints, no significant effect within participant groups on muscle capacity ratio was found. Muscle capacity ratios at MCP joints were less than 1 in all tested participants $(0.27 \pm 0.07$ on average for all participants). 


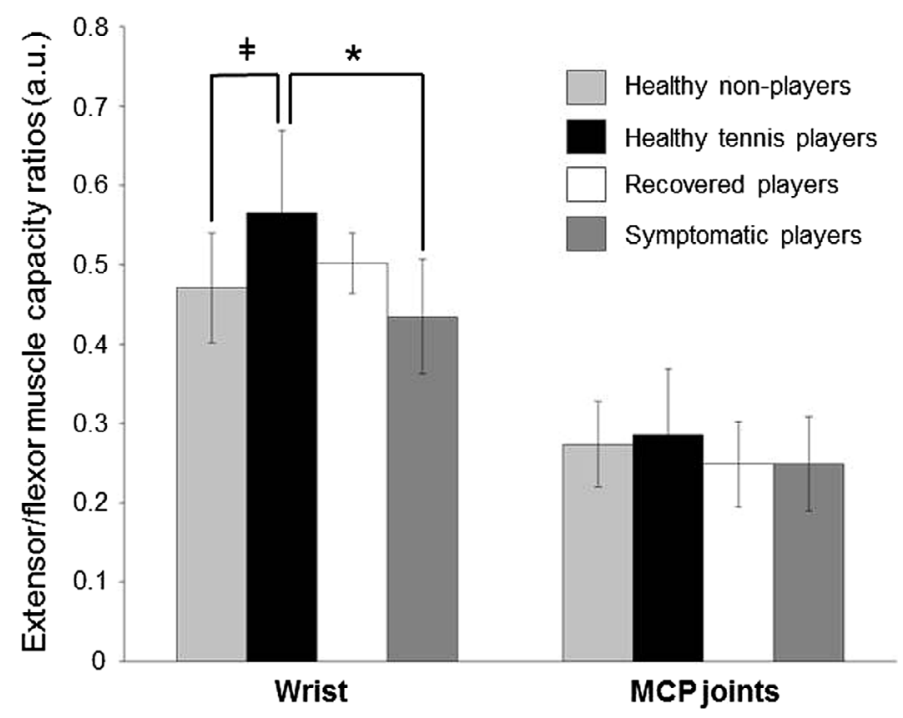

Figure 5. Extensor/flexor muscle capacity ratios at the finger (MCP) and wrist joints. Healthy non-players, Healthy tennis players, Recovered players, and Symptomatic players are represented by the clear grey, black, white, and dark grey blocks, respectively. A ratio close to 1 means that the extensors and the flexors present similar moment-generating capacities. Significant differences between the indicated participant groups were noted $(*: p<0.05 ; \neq: p<0.1)$.

\section{Discussion and implications}

The understanding of hand biomechanics during object or handle manipulation has significantly improved over the last decade, mostly through numerous ergonomic and clinical studies (Kong \& Lowe, 2005; Sancho-Bru et al., 2014; Wu, Dong, McDowell, \& Welcome, 2009). In particular, the estimation of muscle forces using musculoskeletal models confirmed that wrist extensors are highly involved when grasping handle (Goislard de Monsabert et al., 2012) and when performing tennis strokes (Rossi et al., 2014), supporting the idea that a weakness of extensor muscles relative to flexor muscles could increase the risk of occurrence of lateral epicondylalgia. This study investigated the extensor/flexor capacity ratios about both the wrist and the MCP joints in participants with different levels of tennis expertise (advanced players vs. non-players) and various stages of lateral epicondylalgia (healthy, symptomatic, and recovered).

The first key result of this study shows that players have different hand muscle capacities compared with non-players. In accordance with the study of Rogowski, Ducher, Brosseau, and Hautier (2008), who have characterised the increased forearm muscle volume in tennis players, our findings suggest that the experience of several years of playing gives rise to specific muscular adaptations. More precisely, our results indicate that these adaptations are not uniform among hand and forearm muscles since, compared with Non-players, Healthy tennis players showed a 30\% increase of their wrist extensor capacity but no particular modification for other muscle groups. This result is quite surprising since one would expect that tennis players would need to enhance the capacity of wrist flexors to generate higher wrist moments and achieve more powerful forehand, serve or smash strokes (Giangarra et al., 1993). In contradiction with this assumption, tennis practice and expertise might influence 
the capacity and coordination of other muscles such as those of the elbow and shoulder (Rogowski, Creveaux, Cheze, \& Dumas, 2014; Genevois, Reid, Rogowski, \& Crespo, 2015). The particular strengthening of wrist extensors observed in our study probably result from their agonistic role in backhand stroke movements (Knudson, 2004) as well as the necessity to ensure equilibrium about the wrist joint while gripping and manipulating the racket (Rossi et al., 2014). This specific muscular adaptation also probably results from adaptations in patterns of muscle activation. Bazzucchi et al. (2008) indeed observed an increased level of wrist extensor activation which, after numerous repetitions, was able to improve the extensor capacities and contributes in explaining our observations.

From a clinical point of view, two interesting results were found regarding the hypothesis that muscle capacities are linked to the occurrence of lateral epicondylalgia. Firstly, it was observed that Symptomatic and Recovered tennis players showed a 20\% higher wrist flexor capacity compared with Healthy tennis players and Non-players. Secondly, the Symptomatic players showed lower muscle capacity ratios about the wrist (i.e. around 0.43 on average) than both Healthy tennis players (around 0.55) and Recovered players (i.e. around 0.50). These two results indicate that there might be a link between extensor/flexor capacity ratios and the stage of lateral epicondylalgia which therefore partially validates our hypothesis. As the participants were not followed through a longitudinal study, it is difficult to determine whether the observed differences have initiated or are resulting from lateral epicondylalgia. Nevertheless, Symptomatic players exhibited both high wrist flexor capacities and a low capacity ratio which suggests that the wrist extensors are highly engaged in order to counteract the wrist moment created by the stronger flexors. From this reasoning, tennis players exhibiting such marked imbalance are probably more exposed to overuse of the extensor tendons and therefore to the occurrence of lateral epicondylalgia. The combination of both characteristics (strong wrist flexor and strongly imbalanced ratio) could thus be considered as a risk factor and/or as part of the early diagnosis of lateral epicondylalgia. The results obtained for Healthy tennis players and Recovered players tend to confirm this idea since their more balanced extensors/flexors ratio could explain why they were effectively free of the disease. The muscle capacity ratios observed for these two groups could thus be considered as an appropriate adaptation of the muscular capacities to prevent or recover from lateral epicondylalgia. On the contrary, Symptomatic players and Non-players exhibited low muscle capacity ratios which tend to indicate they are more at risk of the occurrence of lateral epicondylalgia and that their extensor capacities should be corrected to protect them for overuse and injuries. Nevertheless, although the results presented here are promising, longitudinal studies would be necessary to fully validate this hypothesis.

Our findings partially contradicted those of Alizadehkhaiyat et al. (2007, 2009). These authors noted an overall weakness of wrist flexion and an increase in ECRB muscle activation in Recovered players. It was concluded that, despite attenuation of pain, an overall upper limb weakness indicated an incomplete functional recovery. In contrast, our results indicated that Recovered players show both higher capacity of wrist flexor muscles and higher wrist capacity ratio thus demonstrating a complete functional recovery and an adaptation of muscle force capacities. A first explanation of these important differences might be that the Recovered players tested in this study had already returned to playing tennis for more than one year, as against 6 months in Alizadehkhaiyat et al. (2009). Another explanation is that the measurement approach used by these authors differed substantially from the one used in this study. Alizadehkhaiyat et al. $(2007,2009)$ directly estimated muscle force capacities 
and ratios using the measured net wrist moments. However, as already explained in the introduction, net joint moments are not representative of muscle force capacities since these measurements corresponded to the resultant action of all the muscles involved, including both synergistic and antagonistic actions. By using a musculoskeletal model of the hand, this study took into account the influence of muscle co-contraction and therefore provided a more accurate estimate of the capacities. However, it should be noted that the use of such musculoskeletal models is subject to inherent limitations, such as assuming rigid segments and frictionless joints. Unfortunately, it is not possible to fully validate estimates of muscle capacities since the direct measurement of all forearm muscle forces is technically difficult and ethically unreasonable. Nonetheless, the differences between estimated and measured activations were in agreement with results of studies comparing estimates from EMG and musculoskeletal models (Valero-Cuevas et al., 1998; Vigouroux, Quaine, Labarre-Vila, Amarantini, \& Moutet, 2007). This suggests that the estimated co-contraction levels were realistic and therefore that the levels of muscle capacities were also physiologically realistic. Therefore, although full validation is not possible, these points increase the confidence in our estimation of specific muscle force capacities.

\section{Conclusion}

In conclusion, our study showed that the muscle moment capacities and flexor/extensor capacity ratios can be useful for evaluating the risk of the occurrence of lateral epicondylalgia and quantifying the adaptation necessary to recover from or prevent the pathology. Apart from muscle capacities, it should however be noted that lateral epicondylalgia is a pathology resulting from a combination of multiple factors, some of them associated with the players' history, anthropometry, and/or amount of training. Muscle force capacity ratio should therefore be considered as an additional etiological factor in lateral epicondylalgia and/or an additional way in which to diagnosis lateral epicondylalgia. Our method could be further used to characterise individual muscle capacity profiles for training programmes and learning processes.

\section{Acknowledgements}

This work forms part of a collaboration between the Decathlon-Oxylane group and Aix-Marseille University through the contract supporting the 'corps au sport' chair.

\section{Disclosure statement}

No potential conflict of interest was reported by the authors.

\section{References}

Alizadehkhaiyat, O., Fisher, A. C., Kemp, G. J., Vishwanathan, K., \& Frostick, S. P. (2007). Upper limb muscle imbalance in tennis elbow: A functional and electromyographic assessment. Journal of Orthopaedic Research, 25, 1651-1657.

Alizadehkhaiyat, O., Fisher, A. C., Kemp, G. J., Vishwanathan, K., \& Frostick, S. P. (2009). Assessment of functional recovery in tennis elbow. Journal of Electromyography and Kinesiology, 19, 631-638. 
Amarantini, D., \& Martin, L. (2004). A method to combine numerical optimization and EMG data for the estimation of joint moments under dynamic conditions. Journal of Biomechanics, 37, $1393-1404$.

Baker, C. L., Murphy, K. P., Gottlob, C. A., \& Curd, D. T. (2000). Arthroscopic classification and treatment of lateral epicondylitis: Two-year clinical results. Journal of Shoulder and Elbow Surgery, 9, 475-482.

Bazzucchi, I., Riccio, M. E., \& Felici, F. (2008). Tennis players show a lower coactivation of the elbow antagonist muscles during isokinetic exercises. Journal of Electromyography and Kinesiology, 18, $752-759$.

Carroll, R. (2006). Tennis elbow: Incidence in local league players. British Journal of Sports Medicine, $15,250-256$.

Chard, M .D., \& Lachmann, S. M. (1987). Racquet sports-patterns of injury presenting to a sports injury clinic. British Journal of Sports Medicine, 21, 150-153.

Chao, E. Y., An, K. N., Cooney, W. P., \& Linscheid, R. L. (1989). Biomechanics of the hand (pp. 5-52). Singapore: World scientific.

Coombes, B. K., Bisset, L., \& Vicenzino, B. (2012). Elbow flexor and extensor muscle weakness in lateral epicondylalgia. British Journal of Sports Medicine, 46, 449-453.

De Luca, C. J., \& Merletti, R. (1988). Surface myoelectric signal cross-talk among muscles of the leg. Electroencephalography and Clinical Neurophysiology, 69, 568-575.

De Smedt, T., De Jong, A., Van Leemput, W., Lieven, D., \& Van Glabbeek, F. (2007). Lateral epicondylitis in tennis: Update on aetiology, biomechanics and treatment. British Journal of Sports Medicine, $41,816-819$.

Fairbank, S. M., \& Corlett, R. J. (2002). The role of the extensor digitorum communis muscle in lateral epicondylitis. The Journal of Hand Surgery, 27, 405-409.

Falconer, K., \& Winter, D. (1985). Quantitative assessment of co-contraction at the ankle joint in walking. Electroencephalography and Clinical Neurophysiology, 25, 135-149.

Genevois, C., Reid, M., Rogowski, I., \& Crespo, M. (2015). Performance factors related to the different tennis backhand groundstrokes: a review. Journal of Sports Science and Medicine, 14, 194-202.

Giangarra, C. E., Conroy, B., Jobe, F. W., Pink, M., \& Perry, J. (1993). Electromyographic and cinematographic analysis of elbow function in tennis players using single- and double-handed backhand strokes. The American Journal of Sports Medicine, 21, 394-399.

Goislard de Monsabert, B., Rossi, J., Berton, E., \& Vigouroux, L. (2012). Quantification of hand and forearm muscle forces during a maximal power grip task. Medicine and Science in Sports and Exercise, 44, 1906-1916.

Goislard de Monsabert, B., Vigouroux, L., Bendahan, D., \& Berton, E. (2014). Quantification of finger joint loadings using musculoskeletal modelling clarifies mechanical risk factors of hand osteoarthritis. Medical Engineering and Physics, 36, 177-184.

Gruchow, H. W., \& Pelletier, D. (1979). An epidemiologic study of tennis elbow. Incidence, recurrence, and effectiveness of prevention strategies. The American Journal of Sports Medicine, 7, 234-238.

Haahr, J. P., \& Andersen, J. H. (2003). Physical and psychosocial risk factors for lateral epicondylitis: A population based case-referent study. Occupational Environmental Medicine, 60, 322-329.

Hatze, H. (1976). Forces and duration of impact, and grip tightness during the tennis stroke. Medicine and Science in Sports, 8, 88-95.

Hennig, E. M., Rosenbaum, D., \& Milani, T. L. (1992). Transfer of tennis racket vibrations onto the human forearm. Medicine and Science in Sports and Exercise, 24, 1134-1140.

Hoozemans, M. J., \& Van Dieën, J. H. (2005). Prediction of handgrip forces using surface EMG of forearm muscles. Journal of Electromyography and Kinesiology, 15, 358-366.

Kaplan, E. B. (1965). Arteritis involving the arteries of the hand. Bulletin of Hospital for Joint Diseases, 26, 52-55.

Kraushaar, B. S., \& Nirschl, R. P. (1999). Tendinosis of the elbow (tennis elbow). Clinical features and findings of histological, immunohistochemical, and electron microscopy studies. Journal of Bone and Joint Surgery-American Volume, 81, 259-278. 
Knudson, D. (2004). Biomechanical studies on the mechanism of tennis elbow. In M. Hubbard, R. D. Mehta, \& J. M. Pallis (Eds.), The engineering of sport (pp. 135-139). Sheffield: International Sports Engineering Association.

Knudson, D., \& Blackwell, J. (1997). Upper extremity angular kinematics of the one-handed backhand drive in tennis players with and without tennis elbow. International Journal of Sports Medicine, $18,79-82$.

Kong, Y. K., \& Lowe, B. D. (2005). Optimal cylindrical handle diameter for grip force tasks. International Journal of Industrial Ergonomics, 35, 495-507.

Lemay, M. A., \& Crago, P. E. (1996). A dynamic model for simulating movements of the elbow, forearm, and wrist. Journal of Biomechanics, 29, 1319-1330.

Mogk, J., \& Keir, P. (2003). The effects of posture on forearm muscle loading during gripping. Ergonomics, 46, 956-975.

Morris, M., Jobe, F. W., Perry, J., Pink, M., \& Healy, B. S. (1989). Electromyographic analysis of elbow function in tennis players. The American Journal of Sports Medicine, 17, 241-247.

Nirschl, R. P. (1973). Tennis elbow. Orthopedic Clinics of North America, 4, 787-800.

Nirschl, R. P. (1992). Elbow tendinosis/tennis elbow. Clinics in Sports Medicine, 11, 851-870.

Olney, S. J., \& Winter, D. A. (1985). Predictions of knee and ankle moments of force in walking from EMG and kinematic data. Journal of Biomechanics, 18, 9-20.

Ramsay, J. W., Hunter, B. V., \& Gonzalez, R. V. (2009). Muscle moment arm and normalized moment contributions as reference data for musculoskeletal elbow and wrist joint models. Journal of Biomechanics, 42, 463-473.

Rao, G., Amarantini, D., \& Berton, E. (2009). Influence of additional load on the moments of the agonist and antagonist muscle groups at the knee joint during closed chain exercise. Journal of Electromyography and Kinesiology, 19, 459-466.

Renstrom, P. A. F. H. (1995). Elbow injuries in tennis. In T. Reilly, M. Hughes, \& A. Lees (Eds.), Science and racket sports (pp. 155-180). London: E \& FN Spon.

Roetert, E. P., Brody, H., Dillman, C. J., Groppel, J. L., \& Schultheis, J. M. (1995). The biomechanics of tennis elbow. An integrated approach. Clinics in Sports Medicine, 4, 47-57.

Rogowski, I., Creveaux, T., Cheze, L., \& Dumas, R. (2014). Scapulothoracic kinematics during tennis forehand drive. Sports Biomechanics, 13, 166-175.

Rogowski, I., Ducher, G., Brosseau, O., \& Hautier, C. (2008). Asymmetry in volume between dominant and nondominant upper limbs in young tennis players. Pediatric Exercise Science, 20, 263-272.

Rossi, J., Vigouroux, L., Barla, C., \& Berton, E. (2014). Potential effects of racket grip size on lateral epicondilalgy risks. Scandinavian Journal of Medicine \& Science in Sports, 24, 462-470.

Sancho-Bru, J. L., Perez-Gonzalez, A., Vergara, M., \& Giurintano, D. J. (2003). A 3D biomechanical model of the hand for power grip. Journal of Biomechanical Engineering, 125, 78-83.

Sancho-Bru, J. L., Mora, M. C., León, B. E., Perez-Gonzalez, A., Iserte, J. L., \& Morales, A. (2014). Grasp modelling with a biomechanical model of the hand. Computer Methods in Biomechanics and Biomedical Engineering, 17, 297-310.

Snijders, C.J., Volkers, A. C., Mechelse, K., \& Vleeming, A. (1987). Provocation of epicondylalgia lateralis (tennis elbow) by power grip or pinching. Medicine and Science in Sports and Exercise, $19,18-23$.

Strizak, A. M., Gleim, G. W., Sapega, A., \& Nicholas, J. A. (1983). Hand and forearm strength and its relation to tennis. The American Journal of Sports Medicine, 11, 234-239.

Vigouroux, L., Goislard de Monsabert, B., \& Berton, E. (2015). Estimation of hand and wrist muscle capacities in rock-climbers. European Journal of Applied Physiology, 115, 947-957.

Vigouroux, L., Quaine, F., Labarre-Vila, A., Amarantini, D., \& Moutet, F. (2007). Using EMG data to constrain optimization procedure improves finger tendon tension estimations during static fingertip force production. Journal of Biomechanics, 40, 2846-2856.

Valero-Cuevas, F. J., Zajac, F. E., \& Burgar, C. G. (1998). Large index-fingertip forces are produced by subject-independent patterns of muscle excitation. Journal of Biomechanics, 31, 693-703.

Wei, S. H., Chiang, J. Y., Shiang, T. Y., \& Chang, H. Y. (2006). Comparison of shock transmission and forearm electromyography between experienced and recreational tennis players during backhand strokes. Clinical Journal of Sport Medecine, 16, 129-135. 
Wu, J. Z., Dong, R. G., McDowell, T. W., \& Welcome, D. E. (2009). Modeling the finger joint moments in a hand at the maximal isometric grip: The effects of friction. Medical Engineering and Physics, 31, 1214-1218. 